\title{
Swedes vote on their nuclear future
}

\section{On 23 March the people of Sweden will be voting in a referendum on nuclear power policy. Wendy Barnaby writes from Stockholm that the exercise is intended to meet party political rather than major policy objectives}

AFTER more than seven years of increasingly acrimonious public debate about nuclear power, nearly all political parties are badly split on the issue and energy policy is totally stranded. Popular support for a referendum was building up at the end of 1978, encouraged by the antinuclear Centre Party and various environmental groups, but it was staunchly opposed by the other parties until the accident at Harrisburg. It then became obvious to the leader of the Social Democratic opposition, Olof Palme, that his only chance of winning the general election scheduled for September, 1979 was to about-face and support a referendum.

Faced with a parliamentary majority in favour of a referendum, the minority Liberal party government (which had already tabled an energy bill incorporating 12 nuclear reactors) had no choice but to go along with it as well. The Centre Party and the Communists, also anti-nuclear, argued that the referendum should be held at the same time as the election, but they were overruled by the combined forces of the Social Democrats, Liberals and Conservatives, all of whose leaderships are pro-nuclear, but whose backbenchers and rank and file are split. These parties would have been embarrassed to have their internal disagreements aired during the election campaign. So the referendum was scheduled for March, 1980 - possibly in the hope that the intervening northern winter and the spectre of oil rationing might have a salutary effect on the population's attitudes. (Sweden depends on imported oil for $70 \%$ of its total energy consumption, which amounts to a little more than $400 \mathrm{TWh}$ a year. Electrical energy, which makes up 90TWh of this, is produced mainly by hydropower. Nuclear power provides $25 \%$ of electrical energy; the rest comes from oil).

In the event, Olof Palme's about-face did not win him the election: the bourgeois bloc won with an overall majority of one seat. Nor were nuclear issues prominent in the campaign. They would, it was said, be discussed once and for all before the referendum. But it is clear that the referendum will not be the final curtain of the nuclear drama. It will simply set the stage for another long act.

After the formation of the new bourgeois government (a coalition of the Centre, Liberal and Conservative parties with Centre leader Torbjörn Fälldin as Prime Minister), the referendum questions had to be drawn up. The party leaderships were divided essentially into two camps: the Communists and the Centre party opposing nuclear power, and the others in favour. But to draw up two alternatives would have meant that the Social Democrats backed the same alternative as the Conservatives. This was politically unpalatable to the Social Democrats, who feared they would lose voters if they were seen to be aligned with the Conservatives on such a crucial issue. They therefore wrote into their referendum manifesto that all power production should be stateowned: not a revolutionary demand, as about $85 \%$ of it is state-owned already. As expected, however, the Conservatives could not go along with this, so the pronuclear side split into two factions.

As a result of this political face-saving, the voters must now decide between three options. Option three, supported by the Centre and Communist parties, Christian organizations and a variety of environmental and radical fringe groups, advocates phasing out the six reactors presently in operation over a period of ten years, and intensifying energy-saving and investment in renewable energy sources. Option two, supported by the Social Democrats and Liberals, advocates "phasing out nuclear power at a pace possible, taking into account the need for electric power for the maintenance of employment and welfare." In practice, this pace would mean, according to option two, using the six reactors now in operation as well as the four ready for loading and the two under construction - a total of 12 for their lifetimes (about 25 years), but not building any more.

Option one, supported by the Conservatives and industry, also advocates (in identical wording to option two), "phasing out nuclear power at a pace possible taking into account the need for electric power for the maintenance of employment and welfare'". This pace would also mean using all twelve reactors. Officially option one also vetoes building another generation of reactors, but its backers make no secret of the fact that this is written in because it would be unwise to declare their enthusiasm for nuclear power in the present political climate. Option one is generally regarded as being more pronuclear and more likely to go ahead with

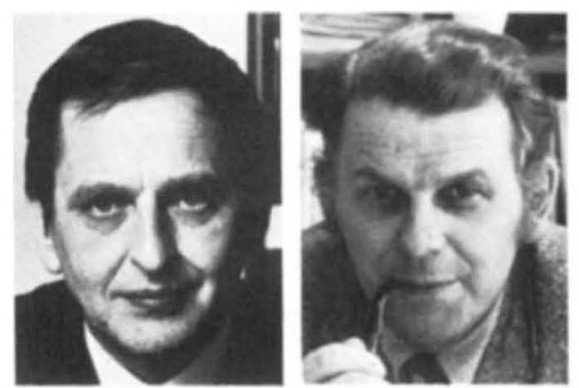

Two Swedish Prime Ministers: former Social Democrat Olof Palme (left) switched to supporting the referendum against his party line. New Centre premier Torbjorn Fallbin (right) is anti-nuclear, but could not implement an anti-nuclear decision

uranium mining in Sweden and breeder reactors than option two.

Having three options produces a situation fraught with difficulties. Although option three has been labelled the 'no' side, it is in fact advocating a further use of nuclear power - for 10 years. Options one and two have also labelled themselves 'phasing out' options, although they advocate a further use of nuclear power on a much larger scale than option three. The debate is not in fact about a 'yes' or a 'no' to nuclear power, but the number of reactor-years nuclear power should be allowed to stay. The public is not faced with a clear-cut choice. Another obvious difficulty with three options is how to interpret the results. The new government had a hard time appointing an Energy Minister, but they finally engaged the services of a non-party judge, CarlAxel Petri. According to him, the support for options one and two will be counted together against option three. Option three must therefore poll more than the other two combined if it is to win. The leader of option three's campaign, Lennart Daléus, has said his option ought to be considered the winner if it polls more than either of the other two options singly. (The latest public opinion poll shows option one being supported by $25 \%$ of the population, option two by $34 \%$, option three by $35 \%$, with $6 \%$ undecided).

Although the referendum is advisory, all parties have said they will follow its result. But whatever the result, there will be political problems. It seems certain that options one and two will together poll more than option three. For Prime Minister Fäldin, opposition to nuclear power is a moral stance, and it is doubtful whether a referendum result could give him absolution to preside over a government taking another six reactors into operation. In the unlikely event of option three's winning, there would be other political problems. The Centre and Communist 
parties do not have a parliamentary majority and would therefore be unable to enact the measures the people had voted for. This would probably lead, sooner or later, to a government crisis and new elections.

While the different factions squabble, the Swedish Council for Planning and Coordination of Research is trying to produce impartial, informative material. It has engaged pairs of authors with different opinions on energy questions to argue their cases on eleven topics, including how to store nuclear waste, how to heat houses, nuclear power and nuclear weapons, and sun, wind and biomass. Each of the pairs has a mediator whose task it is to clarify where the authors agree and disagree.

Whatever the outcome of the referendum, the campaign has demonstrated a lot about the treatment of a complex scientific and technical issue in a democracy. Rational argument about energy has been relatively unimportant. What has been important is politics.

Supporters of option three oppose nuclear power largely, it seems, because they see it as a symbol of many unattractive features of modern, post-industrial life: individual isolation, large-scale technology, powerlessness of the individual to determine living conditions, and so on.

Supporters of options one and two talk about the waste of investment if the country does not use reactors it has built. What they envisage is essentially a continuation of Sweden's post-war history: an economically-expanding society using the latest technology to secure personal welfare.

THE Swedes estimate that the International Nuclear Fuel Cycle Evaluation (INFCE) has increased their chances of obtaining United States approval for reprocessing spent fuel from their reactors. Because they use American enrichment facilities, they are currently forbidden to reprocess spent fuel under the US Nuclear NonProliferation Act of 1978.

After the INFCE discussions, however, the US may well give Sweden permission however guarded - to send spent fuel to existing reprocessing plants and leave the plutonium there.

All Swedish decisions on nuclear matters are in abeyance at the moment, pending the referendum. Irrespective of the result, however, nuclear policy will probably develop along the lines of rejecting a national facility for reprocessing and not insisting on having the plutonium processed abroad sent back. Sweden might well sell its plutonium to the countries which reprocessed it. Such a development would dovetail nicely with some sort of American permission to reprocess.

The two countries are negotiating a new agreement on nuclear cooperation, and it will be as part of this agreement that the reprocessing question will be raised.

Drug innovation-
what's slowing it down?

The research and introduction of new drugs has been slowing down in the UK and the US. At the same time, government regulations on the safety of new drugs have increased. But Fred Steward and George Wibberley argue that there is not a simple relationship between these two trends

THE INFLUENCE of government safety and efficacy regulations on pharmaceutical innovation has become a prominent issue in relations between the industry and the British government. Last April the Association of the British Pharmaceutical Industry (ABPI), in its "election manifesto", criticised the government for producing "a cumbersome and expensive regulatory edifice, much of which serves little useful purpose so far as the well-being of the public is concerned"'. Vice-President Dr Peter Main singled out as a fundamental concern "the effect that the ever-increasing delay caused by regulations relating to the testing of new products was having on pharmaceutical research and innovation". The Association's news sheet has continued to give emphasis to the issue, accompanied by headlines such as 'Murder by Regulation' and 'Take off the Cuffs'.

Last September the new UK Health Secretary, Mr Patrick Jenkin expressed his concern that controls for reasons of safety, quality and efficacy "can reach a point where they are so thorough, so pervasive and so foolproof that everything comes to a full stop", He was anxious that "unnecessary impediments to innovation should be removed".

These views on the drug industry have been accompanied by mounting pressure against government legislation by other sections of British industry, and they have been anticipated in many ways by apparently similar arguments in the United States. The recent federal review of industrial innovation attributed negative effects to laws concerning health, safety and the environment, a conclusion much in tune with President Carter's commitment to "reduce, rationalise and streamline the regulatory burden". Attention has been focused throughout the 1970 s on the impact of such controls on the performance of the drug industry, culminating in the introduction of a variety of proposed drug regulatory reforms in

Fred Steward is lecturer in the Technology Policy Unit, and George Wibberley Professor of Medicinal Chemistry in the Department of Pharmacy at the University of Aston, Birmingham, UK. The authors collaborate in the Pharmaceutical Innovation Group at the university.
Congress during 1978 and 1979.

The time is therefore appropriate to ask what exactly are the effects of regulation on innovation in the drug industry? Two points need to be made at the outset: much of the data and analyses have looked primarily at the US situation; and there are factors other than the legal environment influencing drug innovation. The Pharmaceutical Innovation Group at Aston University has been gathering data on drug innovation in the UK with the aim of evaluating the influence of regulation compared to other factors.

The annual rate of introduction of brand-name pharmaceutical products which doctors in general practice can prescribe in the UK has declined substantially from 1960 to the mid-1970s (Fig 1). This includes duplicates, new formulations, dosages and combinations of existing drugs. New chemical entities (NCEs) - products containing a new chemical substance - comprise only a small proportion of all new products. The annual rate of introduction of NCEs into

Figure 1: pharmaceutical products introduced into the UK 1960-79

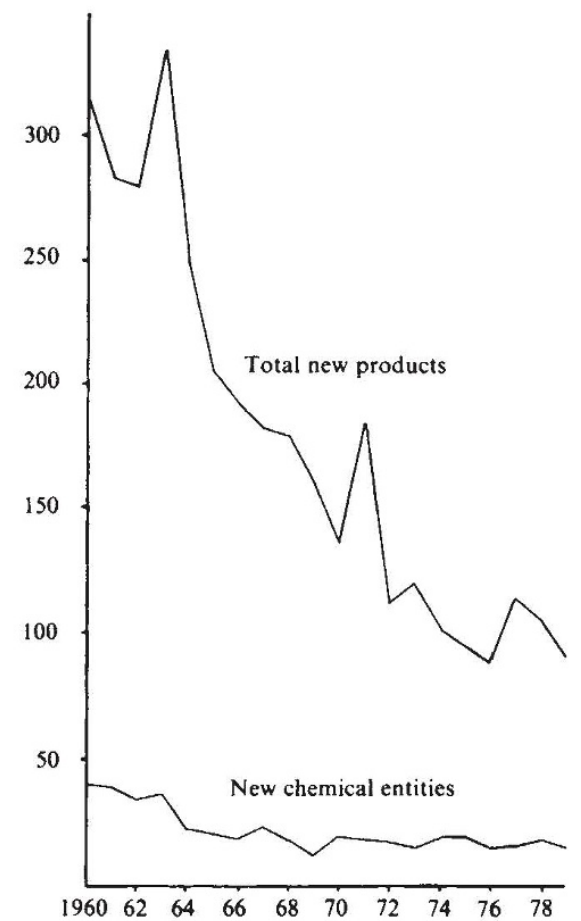

